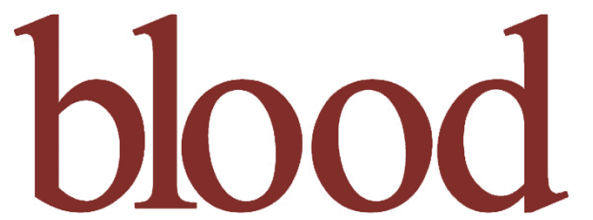

2002 100: 1894-1902

Prepublished online May 13, 2002;

doi:10.1182/blood-2002-02-0419

\title{
Crucial role of timing of donor lymphocyte infusion in generating dissociated graft-versus-host and graft-versus-leukemia responses in mice receiving allogeneic bone marrow transplants
}

An D. Billiau, Sabine Fevery, Omer Rutgeerts, Willy Landuyt and Mark Waer

Updated information and services can be found at:

http://bloodjournal.hematologylibrary.org/cgi/content/full/100/5/1894

Articles on similar topics may be found in the following Blood collections:

Transplantation (1217 articles)

Immunotherapy (564 articles)

Information about reproducing this article in parts or in its entirety may be found online at:

http://bloodjournal.hematologylibrary.org/misc/rights.dtl\#repub_requests

Information about ordering reprints may be found online at:

http://bloodjournal.hematologylibrary.org/misc/rights.dtl\#reprints

Information about subscriptions and ASH membership may be found online at:

http://bloodjournal.hematologylibrary.org/subscriptions/index.dtl

Blood (print ISSN 0006-4971, online ISSN 1528-0020), is published semimonthly by the American Society of Hematology, 1900 M St, NW, Suite 200, Washington DC 20036.

Copyright 2007 by The American Society of Hematology; all rights reserved.

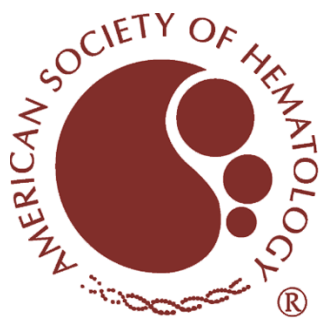




\title{
Crucial role of timing of donor lymphocyte infusion in generating dissociated graft-versus-host and graft-versus-leukemia responses in mice receiving allogeneic bone marrow transplants
}

An D. Billiau, Sabine Fevery, Omer Rutgeerts, Willy Landuyt, and Mark Waer

\begin{abstract}
A murine model of minor histocompatibility antigen-mismatched bone marrow transplantation (BMT) was used to study the role of timing of donor lymphocyte infusion (DLI) in eliciting graft-versushost (GVH) and graft-versus-leukemia (GVL) reactivity. We gave $D L I$ at weeks 3 and 12 after BMT and related its ability to induce a GVL effect with (1) evolution of T cell chimeric status and (2) the extent to which DLI could elicit lymphohematopoietic GVH (LHGVH) reactivity. All mice remained free of GVH disease, but only week 3 DLI chimeras exhibited a significant GVL response when challenged with host-type leukemia cells. In these week 3
\end{abstract}

DLI chimeras, host-reactive $\mathrm{T}$ cells were found to proliferate in vivo (5- [and-6]carboxyfluorescein diacetate, succinimidyl esther [CFSE]-labeled DLI inocula, TCR-V $\beta 6^{+}$T-cell frequency) and T-cell chimerism rapidly converted from mixed into complete donor type, indicating the occurrence of LHGVH reactivity. In week 12 chimeras, DLI elicited none of the activities noted at week 3 . Yet, in both instances, splenocytes, recovered following $\mathrm{DLI}$, generated an equally strong antihost proliferative response in a mixed lymphocyte reaction, thereby arguing against a decisive role of regulatory cells. The lack of in vivo LHGVH reactivity after week 12 DLI was associated with a substantially increased level of pre-existing host-type T-cell chimerism. We conclude that elicitation of a GVL effect may require LHGVH reactivity and that the reason why timing of DLI was critical for obtaining LHGVH reactivity and the desired GVL effect may lie in the evolution of chimeric status. A possible direct involvement of residual host-type antigen-presenting cells in eliciting LHGVH reactivity after DLI should be studied using models that allow chimerism analysis in non-T-cell lineages. (Blood. 2002;100:1894-1902)

(C) 2002 by The American Society of Hematology

\section{Introduction}

The immune recognition and elimination of residual tumor cells by engrafted donor cells, designated the graft-versus-leukemia (GVL) effect, constitutes the main curative potential of allogeneic (allo) hemopoietic stem cell transplantation (HSCT) in hematologic malignancies. ${ }^{1}$ Unfortunately, the GVL effect seems to be closely associated with graft-versus-host disease (GVHD), still a major cause of posttransplantation morbidity and mortality. The infusion of donor lymphocytes (donor lymphocyte infusion [DLI]) following HSCT allows reinduction of remission in patients with posttransplantation leukemic relapse. ${ }^{2-5}$ New HSCT protocols are currently being developed, in which the exploitation of the GVL response occupies an important place. The new pretransplantation and posttransplantation conditioning regimens are tuned to be immunosuppressive rather than nonmyeloablative, thereby aiming at establishing mutual tolerance between host and graft, so as to allow allogeneic cells to eradicate host hematopoietic and malignant cells..$^{6-8}$ As a part of these regimens, DLIs are given to patients with relapse or to those failing to develop full chimerism.9-14 Observations in patients, treated with DLI, have indicated that the incidence and severity of GVHD are high when DLI is applied early after HSCT but significantly lower when DLI is delayed for weeks or months after transplantation. ${ }^{15,16}$ Similarly, in animal models of allo BMT, donor lymphocytes (DLs) can be safely infused, once a sufficient time interval after transplantation has elapsed. ${ }^{17-23}$ Moreover, in murine bone marrow (BM) chimeras, DLI did induce distinct GVL effects. ${ }^{17,21,22}$ These and other clinical and experimental data indicate that, whereas GVH and GVL responses may share effector cells and target antigens, the GVL effect may be dissociated from GVHD.

The reason for waning susceptibility to GVHD in the posttransplantation period is not well understood. Shortly after transplantation, the inflammatory cytokine storm, brought about by the conditioning regimen, may amplify the immune reactivity of host-reactive donor T cells. ${ }^{24}$ Alternatively or in addition to this, the time interval between transplantation and DLI may allow for development of regulatory cells that keep host-reactive $\mathrm{T}$ cells in check. ${ }^{19,20,23,25-30}$ Another poorly defined issue is the nature of the GVL effector cells. Because GVHD ${ }^{31,32}$ and the use of T cellreplete marrow grafts ${ }^{31,33}$ were shown to confer protection against disease relapse, donor $\mathrm{T}$ cells can be presumed to be the primary mediators of the GVL response. Furthermore, in animal models, both $\mathrm{CD}^{+}{ }^{+}$and $\mathrm{CD} 8^{+}$GVL effectors have been described, ${ }^{1,34}$ and in humans, both $\mathrm{CD}^{+}$and $\mathrm{CD} 8^{+} \mathrm{T}$-cell lines and clones with antileukemic specificity have been reported. ${ }^{1,35-39}$ However, in the wake of the T-cell response, other cell populations, such as natural killer (NK) cells, may be recruited and may participate in the GVL
From the Laboratory of Experimental Transplantation and Laboratory of Experimental Radiobiology, University of Leuven, Belgium.

Submitted February 8, 2002; accepted April 23, 2002. Prepublished online as Blood First Edition Paper, May 13, 2002; DOI 10.1182/blood-2002-02-0419.

Supported by grants from the National Fund for Scientific Research (FWO) Flanders, from the ASLK Cancer Research Fund and from the Belgian Federation against Cancer. A.D.B. is a fellow of the FWO.
Reprints: Mark Waer, Laboratory of Experimental Transplantation, University of Leuven, Campus Gasthuisberg, O\&N 8, Herestraat 49, B-3000 Leuven, Belgium; e-mail: mark.waer@med.kuleuven.ac.be.

The publication costs of this article were defrayed in part by page charge payment. Therefore, and solely to indicate this fact, this article is hereby marked "advertisement" in accordance with 18 U.S.C. section 1734.

(C) 2002 by The American Society of Hematology 
response. NK and lymphokine-activated killer (LAK) cells have indeed been implicated as players in the GVL effect in humans and in mice. ${ }^{40-45}$ GVL target antigens may be malignancy specific or overall host specific and the latter antigens may be restricted to hematopoietic lineages or may be broadly expressed. Hematopoietic tissue-restricted minor histocompatibility antigens (miHCags) have been described and donor-derived T-cell clones from patients undergoing allo HSCT have been isolated, targeting not only normal hematopoietic cells but also leukemic cells and leukemic precursors. ${ }^{35,36,46-49}$ In patients treated with DLI, successful GVL responses are often associated with conversion to complete donor chimerism, ${ }^{11,14,15,50}$ supporting the concept of a lymphohematopoietic graft-versus-host (LHGVH) response as part of the GVL mechanism.

Successful application of DLI after allo HSCT requires striking the delicate balance between eliciting the GVL response and causing GVHD, the latter of which still constitutes a major treatment-related complication. ${ }^{6-9}$ Further study into the effector mechanisms of both immune phenomena may help to design regimens that predictably achieve GVL effects without GVHD. Here, we used a murine model of miHCag-mismatched bone marrow transplantation (BMT), previously shown to be well suited for studying the immunoregulatory mechanisms of DLI. In this model, GVHD was avoided when DLI was delayed for 3 weeks after BMT while a distinct GVL response was allowed to develop. ${ }^{21}$ In the present study, DLI was performed at different time points after BMT, as from the moment that DLI was previously shown to be safe. ${ }^{21}$ The capacity of DLs to induce a GVL response was studied and was related to the degree of pre-existing chimerism and to the extent to which DLs were able to elicit alloreactivity in vivo and in vitro. Frequency analysis of T cells expressing specific host-reactive T-cell receptor $\mathrm{V} \beta$ (TCR-V $\beta$ ) chains allowed us to substantiate the LHGVH response and its kinetics and to study its influence on central and peripheral mechanisms of tolerance.

\section{Materials and methods}

\section{Animals}

Animals were purchased from Harlan BV (Horst, The Netherlands; and Bicester, United Kingdom). Ten- to 12-week-old AKR (H-2k, Thy $1.1^{+}$, $\mathrm{Mls} 1 \mathrm{a} / 2 \mathrm{~b}$ ) female mice were used as recipients, and 6- to 12-week-old $\mathrm{C} 3 \mathrm{H}$ (H-2k, Thy $1.2^{+}, \mathrm{Mls} 1 \mathrm{~b} / 2 \mathrm{a}$ ) female mice as donors. Recipients were housed in groups of 5 in plastic cages, bedded with sawdust, and fitted with filter caps. Closed housing units were sterilized prior to use and animals receiving transplants were kept under laminar air flow for at least 2 months after BMT. Diet consisted of standardized pellet chow and water, decontaminated by UV irradiation.

\section{BMT}

Recipient AKR mice were conditioned with 9.5 Gy total body irradiation, using a linear accelerator (General Electric) and a dose-rate of $3.9 \mathrm{~Gy} / \mathrm{min}$ with focus to a midbody distance of $100 \mathrm{~cm}$. One day afterward, recipients were reconstituted with $5 \times 10^{6} \mathrm{~T}$ cell-depleted donor-type $\mathrm{C} 3 \mathrm{H}$ BM cells, administered intravenously in $250 \mu \mathrm{L}$ RPMI 1640 . T-cell depletion was performed using cytotoxic complement-fixing anti-Thy1.2 antibody and low toxic rabbit complement (Serotec, Oxford, United Kingdom), as described previously. ${ }^{21}$

\section{Delayed DLI}

Three and 12 weeks after BMT, chimeric mice were infused via a tail vein with $50 \times 10^{6}$ donor-type splenocytes.

\section{Leukemia challenge}

BW5147.3 cells (AKR mouse lymphoma; American Type Culture Collection, Rockville, MD) were used to study the GVL effect. The tumor cells were taken from frozen stock and maintained in vitro for a limited number of passages, from which cells were taken for experiments. For each in vivo challenge, the in vivo behavior of tumor cells was controlled for by inoculating untreated host-type mice and monitoring leukemia-free survival. One week after DLI, chimeric mice were injected in a tail vein with $5 \times 10^{6}$ leukemia cells. Mice were weighed and observed for clinical signs of leukemic disease. Moribund animals were killed for postmortem examination.

\section{Scoring of T-cell chimerism and frequency of host-reactive donor T cells}

At different time intervals after BMT and DLI, T-cell chimerism and the frequency of $\mathrm{T}$ cells expressing specific TCR-V $\beta$ chains were studied by flow cytometry, using the FACStar plus (Becton Dickinson, Erembodegem, Belgium). Venous blood was obtained from the animals by intracardiac puncture or by cutting the tail. Following red blood cell lysis using $\mathrm{NH}_{4} \mathrm{Cl}$, cells were labeled with fluorescein isothiocyanate (FITC)-, phycoerythrin (PE)- or peridinin chlorophyll protein (PerCP)-conjugated antibodies directed against Thy1.1 (Serotec), Thy1.2 (Serotec), TCR-V $\beta 6$, TCR-V $\beta 3$, TCR-V $\beta 8.3$, or TCR-V $\beta 11, \mathrm{CD} 4, \mathrm{CD} 8$, or CD3 (Pharmingen, Becton Dickinson, Erembodegem, Belgium; and Caltag Laboratories, Synbio bv, AM Uden, The Netherlands).

\section{Mixed lymphocyte reaction}

Responder cells (nylon wool-enriched chimeric or control splenocytes) and stimulator cells (host-type splenocytes) were cultured for 5 days in RPMI 1640 , supplemented with $10 \%$ fetal calf serum (FCS), antibiotics, and $5 \times 10^{-5} \beta 2$-mercaptoethanol, at a concentration of $5 \times 10^{6}$ cells $/ \mathrm{mL}$ and a ratio of $1: 1$, in a final volume of $200 \mu \mathrm{L} /$ well, in flat-bottomed 96-well microculture plates. Prior to culture, stimulator cells were treated with mitomycin C (Kyowa Hakko Kogyo, Tokyo, Japan), as described previously. ${ }^{21}$ DNA synthesis was assayed by adding $1 \mu \mathrm{Ci}(0.037 \mathrm{MBq})$ (methyl-3H) thymidine (Radio Chemical Centre, Amersham, Buckinghamshire, United Kingdom) per well during the last 18 hours of culture. Thereafter, the cells were harvested on glass filter paper, and the counts per minute $(\mathrm{cpm})$ were determined in a liquid scintillation counter. Results are expressed as stimulation index $(\mathrm{SI})$ : $\mathrm{SI}=(\mathrm{cpm}$ of stimulated cells $-\mathrm{cpm}$ of nonstimulated cells)/cpm of nonstimulated cells.

\section{In vitro labeling of cells with CFSE for in vivo transfer and tracking of DLI cells}

Prior to infusion, donor-type splenocytes were labeled with 5- (and-6)carboxyfluorescein diacetate, succinimidyl esther (CFSE; Molecular Probes, Europe, Leiden, The Netherlands). Splenocytes were suspended at a concentration of $50 \times 10^{6}$ cells $/ \mathrm{mL}$ in RPMI 1640 and incubated with CFSE at a final concentration of $5 \mu \mathrm{M}$ for 5 minutes at room temperature. Cells were subsequently washed 3 times with phosphate-buffered saline (PBS), supplemented with FCS $20 \%$, counted, and resuspended for intravenous infusion.

\section{Statistics}

The Mann-Whitney $U$ test and the Kruskal-Wallis multiple comparison $Z$ test were used to estimate the level of statistical significance of difference between groups of data. The log-rank test was used to estimate the level of significance of the difference in survival between groups $(P<.05$ was considered as evidence for statistical significance). 


\section{Results}

\section{Clinical GVH and GVL reactivity following DLI} at 3 and 12 weeks after BMT

We have shown in previous studies that infusion of $50 \times 10^{6}$ donor-type splenocytes at 3 weeks after BMT failed to induce clinical GVHD, while generating a powerful GVL effect. ${ }^{21}$ To see whether this would still be the case at 12 weeks, we conducted an experiment in which week 3 and week 12 chimeras were challenged with $50 \times 10^{6}$ donor-type splenocytes. Control groups consisted of week 3 and week 12 chimeric animals not given DLI. Survival, weight changes, and clinical signs of GVHD were recorded. Figure 1 shows that, like week 3 chimeras, these week 12 chimeras failed to show weight loss or any other sign of GVHD (hunched back, hair loss, diarrhea; results not shown). Survival was $100 \%$ in both groups. The absence of GVHD was confirmed by histology (absence of lymphocytic infiltration in skin, gut, liver; results not shown).

In a similarly designed experiment, week 3 and week 12 DLI chimeras given either DLI or no treatment were inoculated, 1 week after DLI, with $5 \times 10^{6}$ BW5147.3 leukemia cells. Weight and signs of leukemic infiltration were monitored. When moribund, the animals were killed for postmortem examination. The KaplanMeier survival curves (Figure 2) show that whereas DLI prolonged disease-free survival time in week 3 chimeras, it failed to do so in week 12 chimeras. Week 3 DLI chimeras, week 12 DLI chimeras, and untreated control AKR mice were tested together in 2 experiments, reconfirming the previously reported GVL effect of week $3 \mathrm{DLI}^{21}$ and revealing the absence of a significant GVL response after DLI at 12 weeks. Two additional experiments were performed, which further confirmed the inability of DLI, when performed at week 12 after BMT, to elicit a GVL response. That animals died of leukemic disease was confirmed on postmortem histopathologic examination.

\section{Donor (host-reactive TCR-V $\beta 6^{+}$) T cells actively proliferate following infusion at week 3 , but not following infusion at week 12}

To substantiate the elicitation of nonclinical LHGVH reactivity, we investigated the degree to which $\mathrm{T}$ cells actively proliferate, when infused into a week 3 or a week 12 chimeric host. Reportedly,

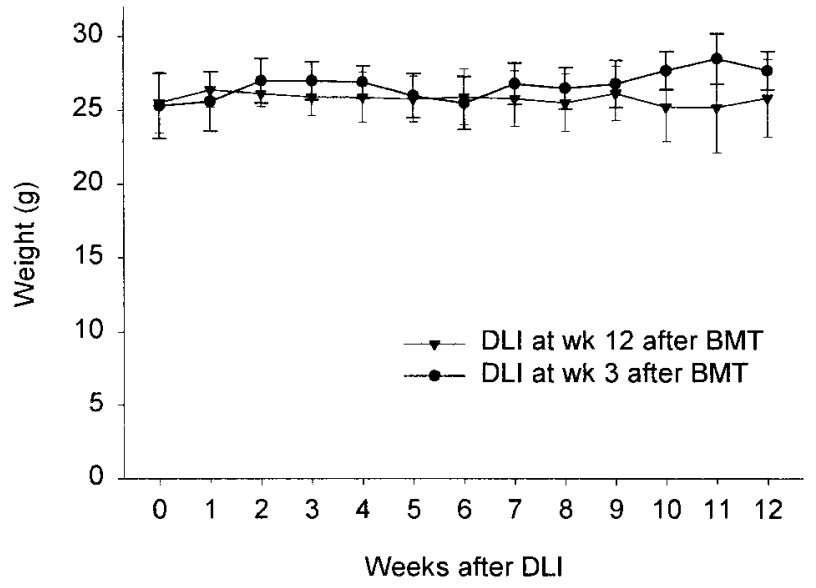

Figure 1. Weight change in individual mice given DLI 3 or 12 weeks after BMT. Results represent mean \pm SD from 2 (3 weeks) and 3 (12 weeks) identically designed experiments ( $n=4-5 /$ group and total $n=9-14$ ).

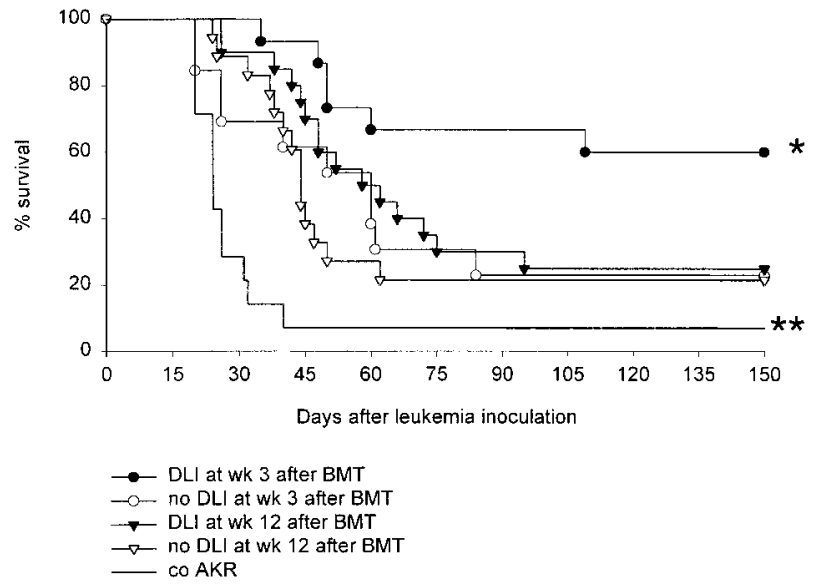

Figure 2. Effect of DLI at 3 and 12 weeks on survival after leukemic challenge. Chimeras given DLI at 3 or 12 weeks and age-matched chimeras not given DLI were inoculated with $5 \times 10^{6}$ BW5147.3 leukemia cells at week 4 and 13, respectively. As a control, untreated host-type AKR mice were given the same leukemia challenge. Kaplan-Meier survival curve is shown of a total of 20 (DLI) and 18 (no DLI) week 12 chimeras, a total of 14 (DLI) and 13 (no DLI) week 3 chimeras, and a total of 14 untreated AKR control mice. Results are shown from 4 similarly designed experiments: all groups were tested together in 2 experiments, week 12 chimeras were tested in 2 additional experiments ( $n=4-7 /$ group). ${ }^{*} P<.05$ for comparison between DLI week 3 and all other groups, and ${ }^{* *} P<.05$ for comparison between co AKR and all other groups, as tested by the log-rank test.

CFSE can be used to stably label cells, so as to allow their identification following in vivo transfer. In proliferating cells, CFSE fluorescence is halved at each successive cell generation. ${ }^{51}$ This technique was used to distinguish infused DLs from BMderived DLs in chimeric animals and to compare their proliferation kinetics in week 3 and week 12 chimeras. Both groups of animals were injected with $50 \times 10^{6} \mathrm{CFSE}^{+}$donor-type spleen cells; control chimeras received unlabeled DLs or no cells. After the animals were rested for 14 days, peripheral blood was collected and using anti-CD3-PerCP and anti-V $\beta 6$-TCR-PE monoclonal antibodies, the frequency and fluorescence intensity of persisting $\mathrm{CFSE}^{+}$ cells was determined in the T-cell population and in the TCR-VB6expressing T-cell population. Figure 3, panels A and B, shows that $\mathrm{CFSE}^{+} \mathrm{CD}^{+}$cells persisted both in week 3 and week 12 chimeras. However, the frequency of $\mathrm{CFSE}^{+}$cells among total $\mathrm{CD}^{+}$cells was markedly higher in week 3 chimeras as compared to week 12 chimeras: $5.7 \%(\mathrm{SE}=0.7, \mathrm{n}=12)$ in week 3 and $2.1 \%(\mathrm{SE}=0.1$, $\mathrm{n}=11$ ) in week 12 chimeras (mean of values obtained in 2 identically designed experiments; $P<.0001$ for comparison between groups as tested by the Mann-Whitney $U$ test). Furthermore, analysis of the distribution of $\mathrm{CD}^{+}$cells according to their fluorescence intensity revealed that, in week 3 chimeras, a significant proportion of $\mathrm{CFSE}^{+}$cells had completed 3 cell divisions; 4 peaks were identified on the histogram, corresponding to serial 2 -fold decreases of fluorescence intensity. In contrast, in week 12 chimeras, only one peak could be discerned, the position of which corresponds to the peak with highest fluorescence intensity in week 3 chimeras (Figure 3C-D). Peripheral blood lymphocytes (PBLs) of chimeras, given DLI with unlabeled donor-type spleen cells, were used as negative controls for analysis of the CFSE fluorescence profiles ( $n=5$ /group). Analysis of PBL CFSE fluorescence on day 7 after week 12 DLI equally revealed one population of $\mathrm{CFSE}^{+} \mathrm{CD}^{+}$cells only, with a CFSE fluorescence profile identical to that of the population seen on day 14. These data indicate that DLI cells, injected at 3 weeks, proliferate for at least 14 days, whereas they do not appear to proliferate during this period when injected into week 12 chimeras. Donor-antihost reactivity, as it 

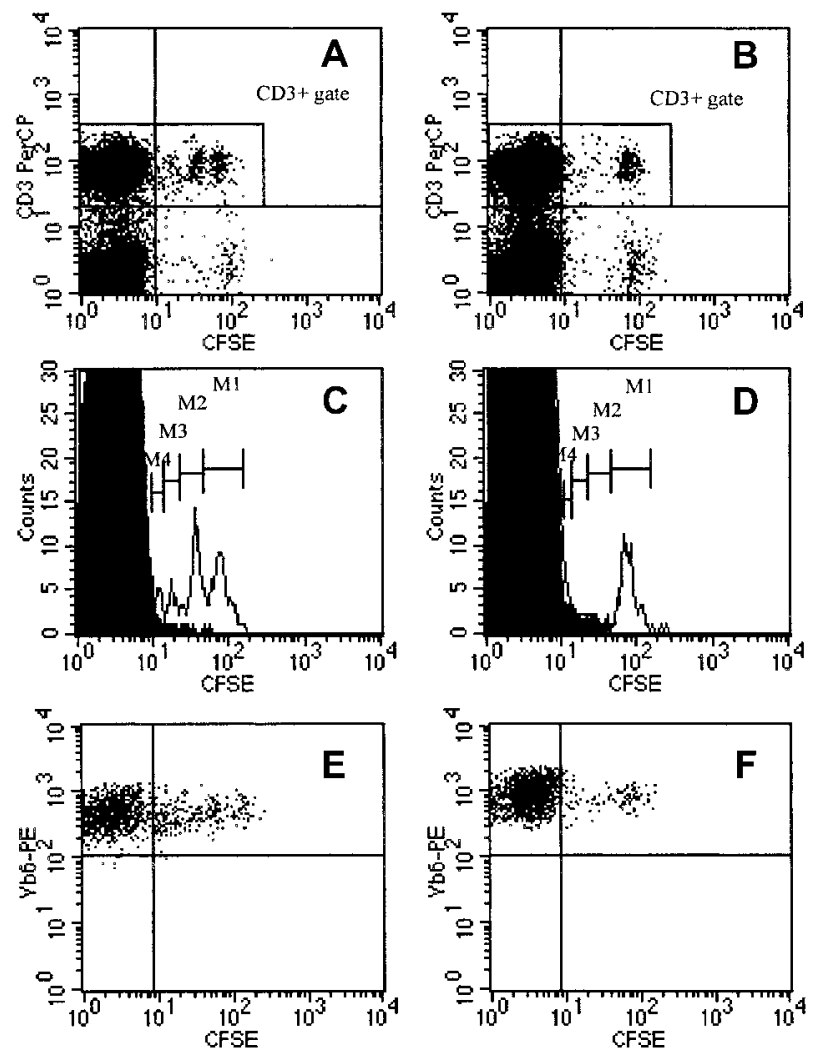

Figure 3. Survival and proliferation of CFSE-labeled DLI cells. Survival and proliferation of CFSE-labeled DLI cells in a week $3 \mathrm{DLI}(\mathrm{A}, \mathrm{C}, \mathrm{E})$ and a week $12 \mathrm{DLI}$ chimera $(B, D, F), 14$ days after DLI with CFSE-labeled cells. $(A, B)$ Distribution of PBLs and the $\mathrm{CD}^{+}$population according to CFSE fluorescence in a week 3 DLI (A) and a week $12 \mathrm{DLI}$ chimera (B). (C,D) Histograms represent the $\mathrm{CD}^{+}$population only, obtained by gating in the corresponding dot plots, shown immediately above $\left(\mathrm{CD}^{+}\right.$gate in panels $\mathrm{A}$ and $\mathrm{B}$, respectively). Open histograms show the distribution of $\mathrm{CD}^{+}$cells according to CFSE fluorescence in the week $3 \mathrm{DLI}(\mathrm{C})$ and the week 12 DLI chimera (D); M1 to M4 indicate cell populations with 2-fold decreasing CFSE fluorescence intensity; superimposed solid histograms represent spontaneous fluorescence of $\mathrm{CD}^{+}$cells from an age-matched control animal (given DLI with unlabeled cells). (E,F) Dot plots were obtained in the TCR-V $\beta 6^{+} \mathrm{CD}^{+}$gate, identified, and gated using double labeling (not shown). Plots show TCR-V $\beta 6^{+} \mathrm{CD}^{+}$ cells according to their CFSE fluorescence in the week $3 \mathrm{DLI}(\mathrm{E})$ and the week $12 \mathrm{DLI}$ chimera (F). Dot plots and histograms are shown from 1 of 5 animals within each group ( 1 of 2 representative experiments).

occurs in GVHD, was associated with expansion of TCR-Vß6expressing $\mathrm{T}$ cells (see "Expansion and clonal deletion of $\mathrm{T}$ cells expressing specific TCR-V $\beta$ chains in GVHD and after BMT and DLI"). Although the absolute counts were low, frequency analysis of TCR-V $\beta 6^{+} \mathrm{CD}^{+}$cells showed that, 14 days after DLI, the relative number of TCR-V $\beta 6^{+}$cells among total $\mathrm{CD}^{+}$cells was higher in week 3 than in week 12 chimeras $(2.5 \% \pm 0.29 \% \mathrm{SE}$, respectively, $1.2 \% \pm 0.07 \% \mathrm{SE}, \mathrm{n}=9-10 /$ group, one of 2 representative experiments; $P<.001$ for comparison between groups as tested by the Mann-Whitney $U$ test; results not shown). Furthermore, $\mathrm{V} \beta 6-\mathrm{TCR}^{+} \mathrm{CD}^{+}{ }^{+} \mathrm{CFSE}^{+}$cells in week 3 chimeras exhibited CFSE fluorescence of varying intensity, whereas in week 12 chimeras, TCR-V $\beta 6^{+} \mathrm{CFSE}^{+} \mathrm{T}$ cells exhibit a more uniform fluorescence profile, suggesting that TCR-V $\beta 6^{+}$cells constitute a subpopulation of $\mathrm{T}$ cells that proliferate after infusion into the week 3 chimeric host (Figure 3E-F).

\section{Nonclinical antihost reactivity following $\mathrm{DLI}$ at 3 and 12 weeks after BMT}

To test the possibility that DLI does elicit antihost reactivity, which remains limited to the lymphohematopoietic system, experiments were conducted in which we compared week 3 and week 12 chimeras for the effect of DLI on the degree of chimerism. Figure 4 shows proportions of host and donor lymphocytes just before and 7 days after DLI. As can be seen, mixed chimerism had developed at 3 weeks after BMT. In these recipients not given DLI, the level of donor T-cell chimerism increased only very slowly, whereas in those given DLI, it was converted within 1 week into nearcomplete donor T-cell chimerism (Figure 4A). In week 12 chimeras, near-complete donor T-cell chimerism had already established spontaneously at the time of DLI, and changes, occurring in the subsequent period of 1 week, whether DLI was given or not, were insignificant (Figure 4B). These data indicate that DLI at week 3 induces vigorous $\mathrm{GVH}$ reactivity, characterized by a rapid replacement of host-type by donor-type T cells. Because near-complete donor T-cell chimerism is established at week 12, conclusions with regard to LHGVH reactivity cannot be made based on chimerism status.

\section{Expansion and clonal deletion of $\mathrm{T}$ cells expressing specific TCR-V $\beta$ chains in GVHD and after BMT and DLI}

In addition to genes encoding for miHCags, recipient-type AKR mice carry the endogenous Mtv-7 retrovirus, which encodes the Mls-1 antigen, leading to thymic negative selection of TCR-V $\beta 6$, $-\mathrm{V} \beta 7,-\mathrm{V} \beta 8.1$, and $-\mathrm{V} \beta 9 \mathrm{~T}$ cells. $\mathrm{C} 3 \mathrm{H}$ donor-type mice do not carry the Mtv-7 provirus, but are infected with the Mtv-6 retrovirus,
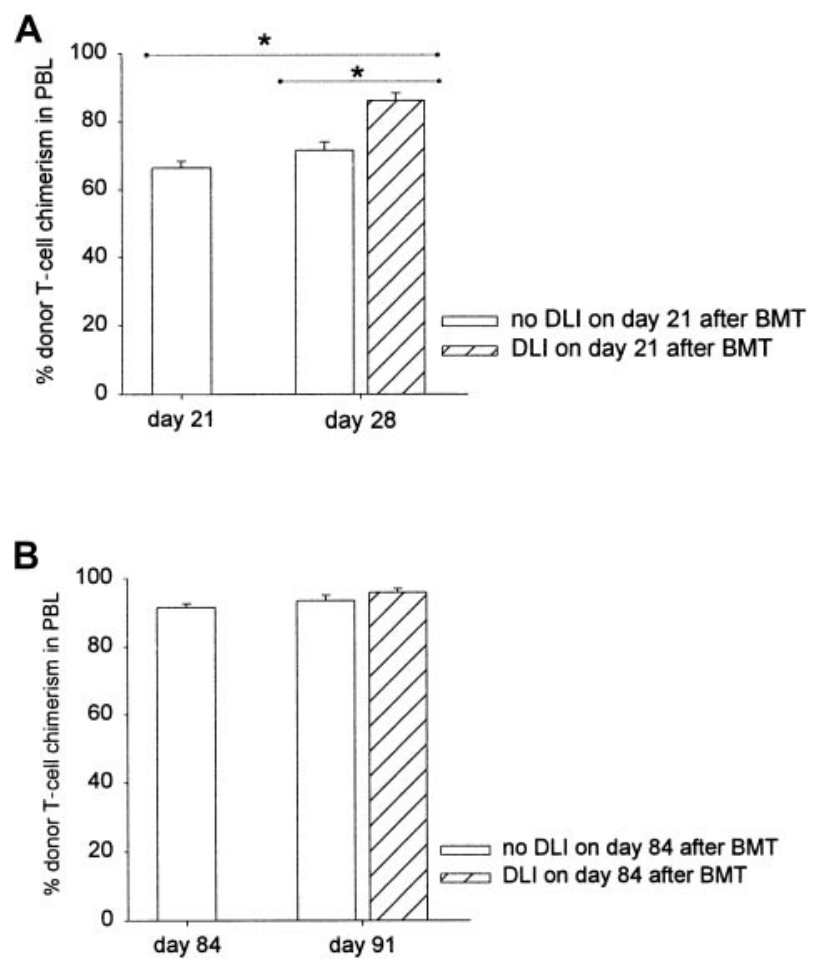

Figure 4. Evolution of donor T-cell chimerism. Spontaneous evolution of donor T-cell chimerism after BMT and changes in chimerism induced by DLI at $3(A)$ and 12 (B) weeks after BMT. T-cell chimerism was determined in PBLs by flow cytometry using anti-Thy1.1-FITC and anti-Thy1.2-PE monoclonal antibodies. In left panels, venous blood was taken from resting animals at 3 (day 21) and 12 weeks (day 84) after BMT. Bars represent mean \pm SE of 6 identically designed experiments ( $n \geq 4$ /group and total $n=43$ and 25 for day 21 and day 84 , respectively). In right panels, venous blood was taken at week 4 (day 28) or 13 (day 91) from animals that had either been given no infusion or DLI at week 3 or week 12 , respectively, after BMT. Bars represent mean \pm SE of 3 to 5 identically designed experiments ( $n \geq 4$ /group and total $n=12-22$ ). ${ }^{*} P<.05$ for comparison between groups as tested by Kruskal-Wallis multiple comparison $Z$ test. 
encoding the Mls-2 antigen, leading to clonal deletion of TCR-V $\beta 3$ $\mathrm{T}$ cells. ${ }^{52}$ Clonal deletion of TCR-V $\beta 11-$ expressing $\mathrm{T}$ cells and persistence of TCR-V $\beta 8.3$-expressing $\mathrm{T}$ cells is common to both strains. We have previously shown that GVHD occurs when DLs are administered on the day of BMT. ${ }^{21}$ Using an identical experimental setup, we confirmed that GVHD, characterized by weight loss, hair loss, and a hunched back is associated with a marked expansion of splenic TCR-V $\beta 6^{+}$T-cell-T cells, when compared to healthy BM chimeras that had received transplants with depleted BM only (Figure 5). In both GVHD and control animals, the proportion of TCR-V $\beta 11^{+}$cells (clonally deleted in both strains) remained low and the frequency of TCR- $\beta 8.3^{+}$-expressing T cells (expressed in both mouse strains) fell within the range of normal untreated host- and donor-type mice. These data clearly show that in animals developing GVHD, a selective expansion occurs of host-reactive $\mathrm{CD}^{+}$and $\mathrm{CD}^{+} \mathrm{T}$ cells expressing the TCR-V $\beta 6$ chain.

Based on the aforementioned results, the frequency of TCR$\mathrm{V} \beta 6^{+} \mathrm{T}$ cells was used to further study the elicitation of antihost reactivity by DLI and to study its course in the long term. Week 3 and week 12 chimeras were given DLI, and venous blood was taken prior to and at 21,45 , and 84 days after DLI. T CD4 ${ }^{+}$and $\mathrm{T}$ $\mathrm{CD}^{+}$cells expressing the TCR-V $\beta 6$ chain were enumerated using flow cytometry. Figure 6 shows that both TCR-V $\beta 6^{+} \mathrm{CD} 4^{+}$and $\mathrm{CD}^{+} \mathrm{T}$ cells were effectively deleted at 3 and 12 weeks after BMT, prior to DLI. After DLI in week 3 chimeras, a progressive increase was seen in the frequency of TCR-V $\beta 6^{+} \mathrm{CD} 4^{+}$and $\mathrm{CD} 8^{+} \mathrm{T}$ cells, reaching significance on day 42 and 21 , respectively. The rise in frequency was sustained up to 84 days after DLI. In week 12 chimeras, a slight but statistically nonsignificant increase in frequency was noted late after DLI. The use of appropriate positive $(\mathrm{C} 3 \mathrm{H})$ and negative $(\mathrm{AKR})$ target cell controls allowed the identification of TCR-V $\beta 6^{+} \mathrm{CD} 4^{+}$and $\mathrm{CD} 8^{+} \mathrm{T}$ cells as a clearly detectable population in week 3 chimeras, given DLI.

To test whether the long-term increased frequency of TCR-V $\beta 6-$ expressing T cells, observed after DLI in week 3 chimeras, was the consequence of peripheral expansion of these cells (as suggested by CFSE labeling) or whether it was the reflection of an altered clonal deletion process in the recipient thymus, week 3 chimeras were given DLI, rested, and killed 84 to 140 days after DLI. Control animals were age-matched chimeras, not given DLI at 3 weeks. The frequency of TCR-V $\beta 6$-expressing single-positive $\mathrm{CD}^{+}$and $\mathrm{CD}^{+} \mathrm{T}$ cells was determined by flow cytometry in spleen and thymus. To verify whether the increased frequency of
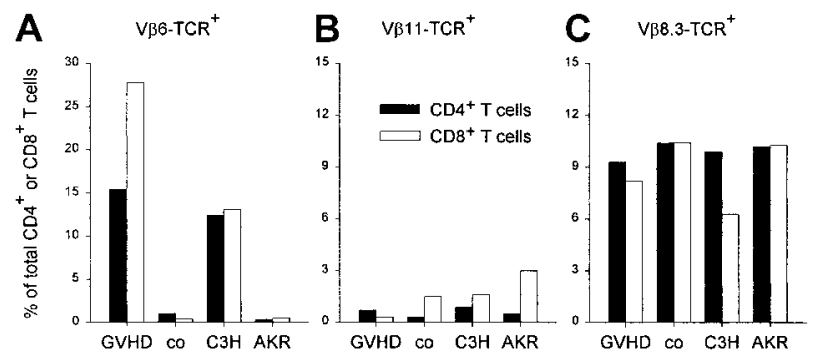

Figure 5. Expansion of splenic TCR-V $\beta 6^{+} \mathrm{T}$ cells in GVHD. The splenic frequency of $\mathrm{TCD}^{+}{ }^{+}$and $\mathrm{CD} 8^{+} \mathrm{T}$ cells, expressing specific TCR-V $\beta$ chains was determined by flow cytometry using FITC-labeled anti-V $\beta$-TCR monoclonal antibody and antiCD4-PE and anti-CD8-PerCP monoclonal antibodies. Results are presented as percentage of total $\mathrm{CD}^{+}$(solid bars) and $\mathrm{CD}^{+}$(empty bars) $\mathrm{T}$ cells in animals, suffering from GVHD (GVHD; $n=2)$, in healthy control BM recipients $(\mathrm{co} ; n=2)$, and in untreated donor (C3H)-type and host (AKR)-type mice. TCR-V $\beta 11^{+}$and TCR$\mathrm{V} \beta 8.3^{+} \mathrm{T}$-cell frequencies were determined as controls. Results are shown from 1 of 3 representative, identically designed experiments.
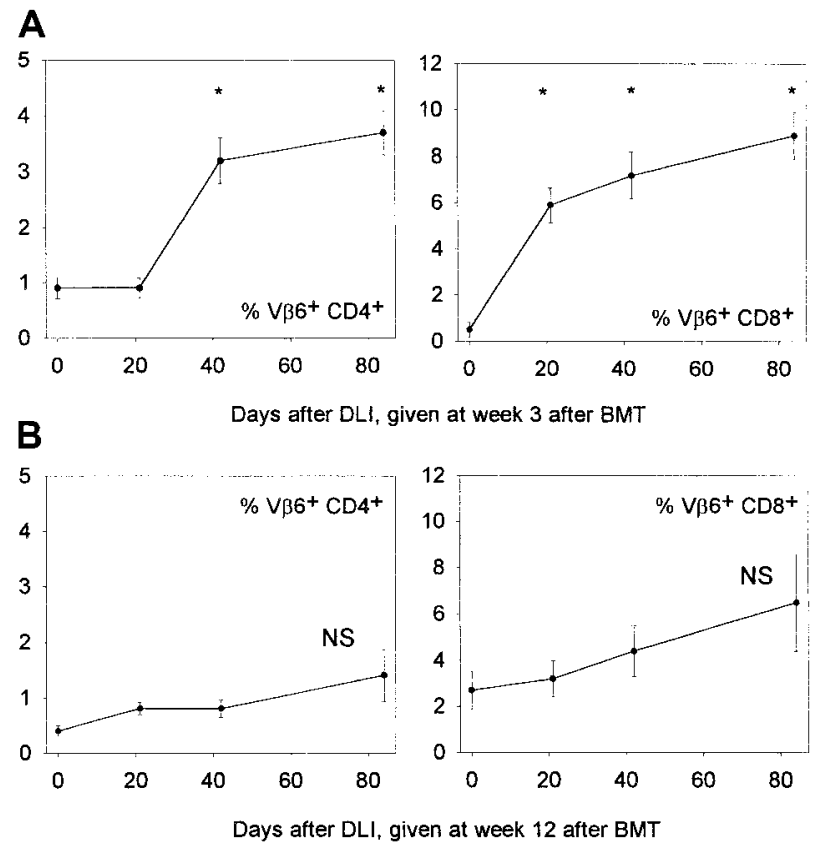

Figure 6. Host-reactive TCR-V $\beta \boldsymbol{6}^{+} \mathrm{T}$ cells in PBLs. Frequency of host-reactive $\mathrm{TCR}-\mathrm{V} \beta 6^{+} \mathrm{T}$ cells in PBLs before and after DLI at 3 (upper panels) or 12 weeks (lower panels). ${\mathrm{V} \beta 6^{+}}^{+} \mathrm{CD}^{+}$(left panels) and ${\mathrm{V} \beta 6^{+}}^{+} \mathrm{CD} 8^{+}$(right panels) $\mathrm{T}$ cells were determined in PBLs by flow cytometry, using anti-TCR-V $\beta 6$-FITC monoclonal antibody and anti-CD4-PE or anti-CD8-PE monoclonal antibody. Venous blood was taken from chimeras prior to and 3,7 , and 12 weeks after DLI at 3 or 12 weeks. Data represent mean \pm SE of 2 (3 weeks) and 3 (12 weeks) identically designed experiments $\left(\mathrm{n}=4-5 /\right.$ group and total $\mathrm{n}=9$ for 3 weeks, 14 for 12 weeks). ${ }^{\star} P<.05$ for comparison between groups as tested by Kruskal-Wallis multiple comparison $Z$ test.

TCR-V $\beta 6^{+} \mathrm{T}$ cells was specific, that is, limited to $\mathrm{T}$ cells expressing host-reactive TCR-V $\beta$ chains, the frequency of TCR$\mathrm{V} \beta 3^{+}$and TCR-V $\beta 8.3^{+}$single-positive $\mathrm{T}$ cells was also determined. Positive and negative target cell controls (AKR, C3H) were included, which also allowed us to relate deletional processes in chimeras to those in normal donor- and host-type mice (one of each control per experiment, 4 identically designed experiments). As can be seen from Figure $7, \mathrm{TCR}-\mathrm{V} \beta 6^{+} \mathrm{CD}^{+}$and $\mathrm{CD}^{+}$T-cell frequency was low in spleens and thymuses of control chimeras, not given DLI (no DLI); levels were similar to those found in untreated control AKR mice. By contrast, in DLI chimeras, TCR-V $\beta 6^{+}$splenocyte and thymocyte frequencies were significantly elevated. These frequencies were similar to those found in untreated donor-type $\mathrm{C} 3 \mathrm{H}$ mice. Neither TCR-V $\beta 3^{+}$nor TCR$\mathrm{V} \beta 8.3^{+} \mathrm{T}$-cell frequency was significantly influenced by DLI, both in splenic and thymic tissue; values were found to fluctuate between those of control mice.

\section{Ex vivo antihost reactivity early after DLI at 3 and 12 weeks after BMT}

To functionally evaluate the ability of DL to mount antihost reactivity after their infusion into a week 3 or week 12 chimeric host, we tested the capacity of lymphocytes to mount a proliferative response, ex vivo, in a standard mixed lymphocyte reaction (MLR). Considering that, reportedly, lymphocytes recirculate within hours to the spleen, ${ }^{53}$ we studied the donor-antihost immune reactivity within the first days after DLI. Spleen cells were taken from week 3 and week 12 chimeras, 48 hours after DLI, and stimulated with host-type antigens in a standard MLR. Splenocytes of normal 
A
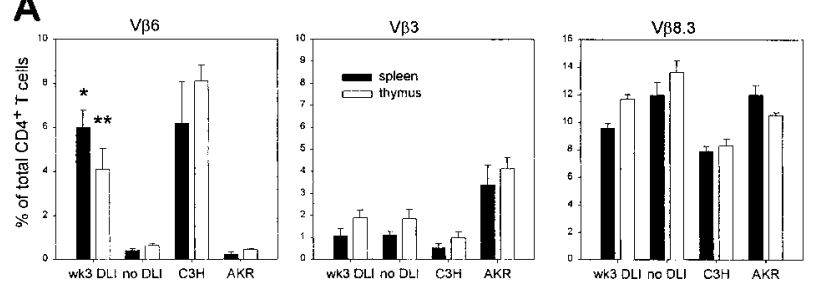

B
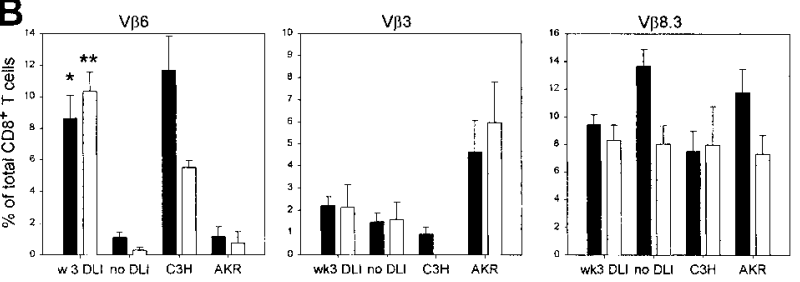

Figure 7. Presence of $\mathrm{T}$ cells expressing specific TCR-V $\beta$ chains in periphery and thymus, 3 to 4 months after DLI. The frequency of T CD4 ${ }^{+}$and $C D 8^{+} \mathrm{T}$ cells, expressing specific TCR $V \beta$ chains was determined by flow cytometry using FITC-labeled anti-V $\beta$-TCR and anti-CD4-PE and anti-CD8-PerCP monoclonal antibodies. Results are expressed as percentage of $\mathrm{T}$ cells, expressing the specific TCR-V $\beta$ chain, among total single-positive $\mathrm{CD}^{+}$(upper panels) or total singlepositive $\mathrm{CD}^{+} \mathrm{T}$ cells (lower panels), in spleens (black bars) or thymuses (empty bars) of chimeras, given DLI at week 3 (DLI). Control chimeras (no DLI) had not been challenged with DLI at week 3 . Data represent mean \pm SE of 10 individual DLI chimeras and 6 individual cochimeras from 3 identically designed experiments. ${ }^{*} P<.05$ for comparison between spleen values of DLI and no $\mathrm{DLI} ;{ }^{* *} P<.05$ for comparison between thymus values of DLI and no DLI, as tested by the MannWhitney $U$ test.

untreated donor-type mice were used as controls for donor-antihost reactivity. As can be seen from Figure 8, spleen cells of both week 3 and week 12 DLI chimeras were capable of mounting a proliferative response in vitro, which was equally strong, although significantly weaker than that of control donor-type splenocytes. Splenocytes from chimeras not given DLI were unable to generate a proliferative response.

\section{Discussion}

The model used for this study consisted of irradiated AKR mice, reconstituted with T cell-depleted $\mathrm{C} 3 \mathrm{H}$ BM. As previously shown, such mice develop mixed T-cell chimerism at 3 weeks after transplantation. DLI in the first week induces GVHD, whereas DLI at week 3 fails to induce such a lethal response, but produces a beneficial GVL effect. ${ }^{21}$ In view of the waning susceptibility to GVHD in the early posttransplantation period, and because GVHD and the GVL effect may share certain target antigens and effector cells, we asked the questions (1) whether further delay of the DLI would similarly be associated with waning of the GVL effect and (2) whether changes in DLI-elicited responses could be related to continued evolution in the chimeric status of the recipient mice.

Animals receiving DLI either at week 3 or 12 remained free of clinical GVHD during the entire observation period. This is in keeping with previous reports and indicates that DLI can be safely performed after allo BMT, once a sufficient time interval, the length of which may depend on the model used, has elapsed. ${ }^{17-23}$

Whereas the previously reported GVL effect of DLI at week $3^{21}$ was reconfirmed, the data indicated that, when infused at week 12, DLs are not allowed to develop antileukemic activity. The presence or absence of the GVL effect was associated with substantially different immunologic antihost reactivity in vivo. Both in week 3 DLI and week 12 DLI chimeras, infused DLs remained detectable for at least 14 days. A subpopulation of $\mathrm{CFSE}^{+} \mathrm{T}$ cells expanded in vivo in week 3 chimeras during the first 14 days after infusion. In week 12 chimeras, however, $\mathrm{CFSE}^{+} \mathrm{T}$ cells did not appear to divide on day 14 nor at the earlier stage of day 7 after DLI. From these data, it can be concluded that in week 3 chimeras, T cells proliferate in response to host antigens, whereas in week 12 chimeras, these host-reactive T cells are not stimulated or not allowed to proliferate to the same extent. Following week 3 DLI, host-type lymphocytes were rapidly eliminated with conversion of pre-existing mixed into near-complete chimerism within 7 days, indicating that hostreactive cells generated a marked LHGVH reaction.

The frequency of TCR-V $\beta 6$-expressing $\mathrm{T}$ cells was used to substantiate the proposed DLI-induced LHGVH response and to analyze its kinetics. TCR-V $\beta 6$-expressing $\mathrm{T}$ cells are strongly correlated with reactivity to Mls- 1 antigens, ${ }^{52}$ in this situation expressed in the host-type mouse strain only, and, in addition, they have been shown to be associated with GVH reactivity in murine models involving host-type mice expressing the Mls-1 superantigen. ${ }^{54-56}$ Reportedly, both $\mathrm{CD}^{+}{ }^{+}$and $\mathrm{CD} 8^{+} \mathrm{T}$ cells are involved in GVHD and although recognition of Mls-1 antigens requires major histocompatibility complex (MHC) class II molecules and thus recruits mostly $\mathrm{CD}^{+}{ }^{+} \mathrm{T}$ cells, Mls-reactive $\mathrm{CD} 8^{+}$cells have been identified in several instances. ${ }^{57}$ Here, we found that GVHD, occurring when DLI was given at the time of BMT, was indeed associated with a marked and specific expansion of TCR-V $\beta 6^{+} \mathrm{T}$ cells, of both $\mathrm{CD} 4^{+}$and $\mathrm{CD} 8^{+}$phenotype. Hence, we compared TCR-V $36^{+} \mathrm{CD}^{+}$and $\mathrm{CD} 8^{+} \mathrm{T}$-cell frequencies in PBLs, spleen, and thymus of $\mathrm{BM}$ chimeras with those in chimeras that were left untreated.

In chimeras not given DLI, clonal deletion after allo BMT was shown to be a long-lasting and specific process; at all time points, TCR-V $\beta 6^{+} \mathrm{T}$-cell frequency in PBLs and spleens was similar to deletional levels seen in untreated host-type mice. Furthermore, the frequency of TCR-V $\beta 8.3^{+} \mathrm{T}$ cells was of a nondeletional level, such as that found in normal host- and donor-type mice; TCR$\mathrm{V} \beta 3^{+} \mathrm{T}$-cell frequency, however, approached deletional levels such as those found in untreated donor-type mice, reflecting the presence of donor BM-derived antigen-presenting cells (APCs) in the thymus of chimeras, mediating clonal deletion of donor-reactive $\mathrm{T}$ cells. Deletion of Mls-1-reactive T cells has been shown to occur

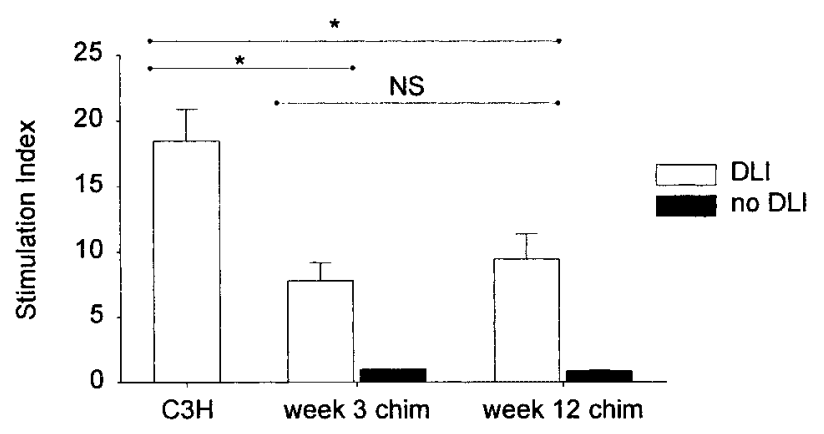

Figure 8. Proliferative capacity of chimeric spleen cells, 48 hours after DLI at 3 or 12 weeks. Two days after DLI at 3 or 12 weeks, spleen cells were stimulated in vitro with mitomycin C-treated host-type splenocytes in a standard MLR. Spleen cells of untreated donor-type mice and of week 3 and week 12 chimeras that had not received DLI were used as controls. Proliferation was determined by (methyl- ${ }^{3} \mathrm{H}$ ) thymidine incorporation. Results are expressed as SI. Bars represent mean $\pm \mathrm{SE}$ of 2 (12 weeks) or 4 (3 weeks) identically designed experiments with $n=13(\mathrm{C} 3 \mathrm{H}), 10$ (week 3 chim + DLI), 6 (week 12 chim + DLI), 3 (week 3 chim no DLI), and 3 (week 12 chim no DLI). Week 3 and week 12 chimeras not given DLI were unable to generate a proliferative response $(\mathrm{SI}=1, \mathrm{SE}=0$ and $\mathrm{SI}=0.9, \mathrm{SE}=0.07$, respectively). ${ }^{*} P<.05$ for comparison between groups as tested by Kruskal-Wallis multiple comparison $Z$ test. NS indicates not significant. 
both in the thymus and in the periphery. ${ }^{58}$ Here, single-positive TCR-V $\beta 6^{+} \mathrm{CD}^{+}$and $\mathrm{CD} 8^{+} \mathrm{T}$ cells were not detectable in thymuses of long-term chimeras, which had not been given DLI. Therefore, in this model, clonal deletion is most likely occurring in the thymus, thereby also implying the continuing presence in the thymus of host-type class II MHC I-E-expressing APCs. ${ }^{58}$

In week 3 chimeras given DLI, conversion of mixed into complete donor chimerism was associated with a progressive expansion of TCR-V $\beta 6$-expressing T cells in PBLs, the initial increase of which was ascribed to T-cell activation and proliferation (see studies with CFSE-labeled DLI cells), as part of the LHGVH reaction; this was supported by the rapidity of the increase in T-cell numbers. However, the subsequent sustained elevation of T-cell frequency for the entire follow-up period of 84 days after DLI, that is, well beyond the time point at which complete chimerism was established, may rather be indicative of an altered clonal deletion pattern in the thymus. Whereas TCR-V $\beta 6^{+}$single-positive T cells were clonally deleted in the thymus of long-term chimeras that had not received DLI, they were definitely present in the thymus of chimeras, 3 to 4 months after week 3 DLI. A possible explanation is that host-reactive DLI T cells migrate into the thymus and eliminate residual host-derived thymic APCs, thus keeping host-type miHCags, such as the Mls-1 antigen, from being presented for negative selection. This would then result in a donor-type clonal deletion profile, in which newly developing, BM-derived TCR-V $\beta 6^{+} \mathrm{T}$ cells escape clonal deletion. The frequency of TCR-V $\beta 3^{+}$and $\mathrm{V} \beta 8.3^{+} \mathrm{T}$ cells was unaltered, as compared with frequencies in chimeras not given DLI, indicating that loss of negative selection of TCR-V $\beta 6^{+} \mathrm{T}$ cells would be a selective defect. It has indeed been demonstrated that activated mature $\mathrm{T}$ cells can migrate into the thymus. ${ }^{59}$ In particular, TCR-V $\beta 6^{+}$host-reactive $\mathrm{T}$ cells have been shown to locate to the thymus in murine GVHD models, involving Mls-1-disparate mouse strains. The GVH reaction, targeting the thymic stroma resulted in the abrogation of negative selection of TCR-V $\beta 6^{+}$autoreactive T-cell clones and the persistence of these cells in the periphery. ${ }^{60,61}$ Further studies should determine whether after DLI, long-term persisting host-reactive T cells in the thymus and periphery are either activated $\mathrm{T}$ cells from the DLI inoculum or newly developing, BM-derived $\mathrm{T}$ cells that escape clonal deletion.

In week 12 DLI chimeras, DLI did not elicit any detectable antihost reactivity, as evident from the lack of proliferation of infused CFSE ${ }^{+} \mathrm{T}$ cells and the lack of expansion of TCR-V $\beta 6^{+} \mathrm{T}$ cells following DLI. Two explanations, which are not mutually exclusive, can be brought forward. By week 12, regulatory cells may have developed, which limit GVH reactivity brought about by DLI cells ${ }^{19,20,23,25-30}$ or remaining host-type APCs within the lymphohematopoietic compartment in these long-term chimeras may have become so sparse as to preclude the generation of antihost immune responses. Host-derived APCs have indeed been shown to be instrumental in eliciting GVH responses in a murine model of miHC-ag-mismatched BMT. ${ }^{62}$ Unfortunately, the study of APC chimerism in our model was precluded by the lack of differential expression of non-T-cell markers by donor and host strains. If, as is assumed to be the case in myeloablative BMT models, APC and T-cell chimerism evolve in parallel, week 12 chimeras would indeed lack host APCs in sufficient numbers to present host-type antigens and to induce donor T-cell activation and proliferation. Although in week 12 chimeras, DLs did not elicit any of the activities seen in week 3 chimeras, they retained the ability to proliferate, after being infused into near-complete chimeric hosts.
Indeed, splenocytes, recovered from week 12 DLI chimeras, 48 hours after DLI, were definitely able to mount an in vitro antihost response when stimulated in vitro with host-type antigens. The response was as strong as that of splenocytes recovered from week 3 DLI chimeras. In both instances, the response was significantly weaker than that of splenocytes taken from untreated donor-type animals, probably reflecting the dilution of responding donor-type $\mathrm{T}$ cells from the DLI inoculum, that had recirculated to the chimeric spleen. Hence, although both at week 3 and week 12 regulatory/ suppressor cells may play a role in limiting or abolishing antihost reactivity in vivo, this mechanism does not operate to the same extent in vitro or ex vivo. The proliferative activity observed with week 12 DLI splenocytes in the ex vivo setting may rather be the result of providing donor-type T cells with host-type APCs and antigens in the MLR culture. Similarly, paucity of host-type APCs may possibly explain why, 3 months after week 3 DLI, hostreactive $\mathrm{T}$ cells that have escaped clonal deletion in the thymus, can persist in the periphery in otherwise healthy hosts; the lack of host-type APCs would preclude professional presentation of hosttype antigens for the generation of antihost responses. As a contrast, in models of overt GVHD, host-reactive T cells that escape clonal deletion as a result of thymic GVH reactivity were shown to exhibit in vitro and in vivo antihost reactivity. ${ }^{60}$

Our observations bring forward important aspects of GVL and GVH responses developing after DLI and after allo BMT in general. They suggest that the GVL reactivity of DLI is, at least in part, occurring as part of the T cell-mediated LHGVH response and that the LHGVH reaction with the subsequent conversion to a more advanced donor chimeric state, rather than the full donor chimeric state itself, may be crucial to the GVL response of DLI. The GVL response may therefore wane as time elapses after DLI and remain operative as long as host-reactive T cells from the DLI inoculum proliferate. Importantly, the data suggest that, for donor cells from the DLI inoculum to be able to eradicate leukemia cells, a certain degree of residual host lymphohematopoietic chimerism may be required so that a sufficiently strong LHGVH reaction is elicited. A key role has been ascribed to host-derived APCs in eliciting GVH responses ${ }^{62}$ and they may therefore also be instrumental in eliciting LHGVH and GVL effects. Therefore, that adequate timing of DLI was so critical for obtaining the GVL effect probably derives from the change in chimeric status taking place after BMT. The direct involvement of residual host-type APCs in generating LHGVH and GVL reactivity should be investigated using a model in which host- and donor-type chimerism can be distinguished both in $\mathrm{T}$ and non-T-cell lineages.

In patients treated with DLI, a GVL response often coincides with an increase in donor chimerism ${ }^{11,14}$ and because clinical data do seem to indicate that the success of procedures such as DLI may depend on chimerism status, frequent lineage-specific chimerism analysis has recently been advocated as a guideline to novel transplantation strategies. ${ }^{63}$ Characterization of lineage-specific chimerism in patients undergoing allo BMT revealed that, in patients with late relapses from acute leukemia or myelodysplastic syndrome, the only cells of host origin were leukemic cells. ${ }^{64}$ Theoretically, in such complete donor chimeric hosts, the simultaneous infusion of host-type APCs with the DLI inoculum may bring about sufficient GVH reactivity to produce a GVL response. Our findings add to the understanding of the effectiveness of DLI in clinical practice and may be useful for the development of DLI as a preventive strategy in patients undergoing allo BMT. 
From www.bloodjournal.org at SWETS SUBSCRIPTION SERVICES on November 26, 2007. For personal use only.

\section{References}

1. Porter DL, Antin JH. The graft-versus-leukemia effects of allogeneic cell therapy. Annu Rev Med. 1999;50:369-386.

2. Slavin S, Naparstek E, Nagler A, et al. Allogeneic cell therapy with donor peripheral blood cells and recombinant human interleukin-2 to treat leukemia relapse after allogeneic bone marrow transplantation. Blood. 1996;87:2195-2204.

3. Slavin S, Naparstek E, Nagler A, Ackerstein A, Kapelushnik J, Or R. Allogeneic cell therapy for relapsed leukemia after bone marrow transplantation with donor peripheral blood lymphocytes. Exp Hematol. 1995;23:1553-1562.

4. Kolb HJ, Mittermuller J, Clemm C, et al. Donor leukocyte transfusions for treatment of recurrent chronic myelogenous leukemia in marrow transplant patients. Blood. 1990;76:2462-2465.

5. Porter DL, Roth MS, McGarigle C, Ferrara JL, Antin $\mathrm{JH}$. Induction of graft-versus-host disease as immunotherapy for relapsed chronic myeloid leukemia. N Engl J Med. 1994;330:100-106.

6. Champlin R, Khouri I, Shimoni A, et al. Harnessing graft-versus-malignancy: non-myeloablative preparative regimens for allogeneic haematopoietic transplantation, an evolving strategy for adoptive immunotherapy. Br J Haematol. 2000; 111:18-29.

7. Peggs KS, Mackinnon S. Cellular therapy: donor lymphocyte infusion. Curr Opin Hematol. 2001;8: 349-354.

8. Feinstein L, Storb R. Nonmyeloablative hematopoietic cell transplantation. Curr Opin Oncol. 2001;13:95-100.

9. Khouri IF, Keating M, Korbling M, et al. Transplant-lite: induction of graft-versus-malignancy using fludarabine-based nonablative chemotherapy and allogeneic blood progenitor-cell transplantation as treatment for lymphoid malig nancies. J Clin Oncol. 1998;16:2817-2824

10. Giralt S, Estey E, Albitar M, et al. Engraftment of allogeneic hematopoietic progenitor cells with purine analog-containing chemotherapy: harnessing graft-versus-leukemia without myeloablative therapy. Blood. 1997;89:4531-4536.

11. Spitzer TR, McAfee S, Sackstein R, et al. Intentional induction of mixed chimerism and achievement of antitumor responses after nonmyeloablative conditioning therapy and HLA-matched donor bone marrow transplantation for refractory hematologic malignancies. Biol Blood Marrow Transplant. 2000;6:309-320

12. Slavin S, Nagler A, Naparstek E, et al. Nonmyeloablative stem cell transplantation and cell therapy as an alternative to conventional bone marrow transplantation with lethal cytoreduction for the treatment of malignant and nonmalignant hematologic diseases. Blood. 1998;91:756-763.

13. Nagler A, Slavin S, Varadi G, Naparstek E, Samuel S, Or R. Allogeneic peripheral blood stem cell transplantation using a fludarabine-based low intensity conditioning regimen for malignant lymphoma. Bone Marrow Transplant. 2000;25:10211028.

14. Childs R, Clave E, Contentin N, et al. Engraftment kinetics after nonmyeloablative allogeneic peripheral blood stem cell transplantation: full donor T-cell chimerism precedes alloimmune responses. Blood. 1999;94:3234-3241.

15. Mackinnon S, Papadopoulos EB, Carabasi MH et al. Adoptive immunotherapy evaluating escalating doses of donor leukocytes for relapse of chronic myeloid leukemia after bone marrow transplantation: separation of graft-versus-leukemia responses from graft-versus-host disease. Blood. 1995;86:1261-1268.

16. Drobyski WR, Hessner MJ, Klein JP, et al. T-cell depletion plus salvage immunotherapy with donor leukocyte infusions as a strategy to treat chronicphase chronic myelogenous leukemia patients undergoing HLA-identical sibling marrow transplantation. Blood. 1999;94:434-441.

17. Pelot MR, Pearson DA, Swenson K, et al. Lymphohematopoietic graft-vs.-host reactions can be induced without graft-vs.-host disease in murine mixed chimeras established with a cyclophosphamide-based nonmyeloablative conditioning regimen. Biol Blood Marrow Transplant. 1999;5:133 143.

18. Sykes M, Sheard MA, Sachs DH. Graft-versushost-related immunosuppression is induced in mixed chimeras by alloresponses against either host or donor lymphohematopoietic cells. J Exp Med. 1988;168:2391-2396.

19. Weiden PL, Storb R, Tsoi MS, Graham TC, Lerner KG, Thomas ED. Infusion of donor lymphocytes into stable canine radiation chimeras: implications for mechanism of transplantation tolerance. J Immunol. 1976;116:1212-1219.

20. Georges GE, Storb R, Thompson JD, et al. Adoptive immunotherapy in canine mixed chimeras after nonmyeloablative hematopoietic cell transplantation. Blood. 2000;95:3262-3269.

21. Sefrioui H, Billiau AD, Waer M. Graft-versus-leukemia effect in minor antigen mismatched chimeras given delayed donor leucocyte infusion: immunoregulatory aspects and role of donor $\mathrm{T}$ and ASGM1-positive cells. Transplantation. 2000;70: 348-353.

22. Johnson BD, Drobyski WR, Truitt RL. Delayed infusion of normal donor cells after MHC-matched bone marrow transplantation provides an antileukemia reaction without graft-versus-host disease. Bone Marrow Transplant. 1993;11:329-336.

23. Blazar BR, Lees CJ, Martin PJ, et al. Host T cells resist graft-versus-host disease mediated by donor leukocyte infusions. J Immunol. 2000;165: 4901-4909.

24. Antin JH, Ferrara JL. Cytokine dysregulation and acute graft-versus-host disease. Blood. 1992;80: 2964-2968.

25. Tutschka PJ, Hess AD, Beschorner WE, Santos GW. Suppressor cells in transplantation tolerance, I: suppressor cells in the mechanism of tolerance in radiation chimeras. Transplantation. 1981;32:203-209.

26. Tsoi MS, Storb R, Dobbs S, Thomas ED. Specific suppressor cells in graft-host tolerance of HLAidentical marrow transplantation. Nature. 1981; 292:355-357.

27. Strober S, Palathumpat V, Schwadron R, HertelWulff B. Cloned natural suppressor cells preven lethal graft-vs-host disease. J Immunol. 1987; 138:699-703.

28. Sykes M, Sharabi Y, Sachs DH. Natural suppressor cells in spleens of irradiated, bone marrowreconstituted mice and normal bone marrow: lack of Sca-1 expression and enrichment by depletion of Mac1-positive cells. Cell Immunol. 1990;127: 260-274.

29. Colby C, Sykes M, Sachs DH, Spitzer TR. Cellu lar modulation of acute graft-vs.-host disease. Biol Blood Marrow Transplant. 1997;3:287-293.

30. Johnson BD, Becker EE, LaBelle JL, Truitt RL. Role of immunoregulatory donor T cells in suppression of graft-versus-host disease following donor leukocyte infusion therapy. J Immunol. 1999;163:6479-6487.

31. Horowitz MM, Gale RP, Sondel PM, et al. Graftversus-leukemia reactions after bone marrow transplantation. Blood. 1990;75:555-562.

32. Sullivan KM, Weiden PL, Storb R, et al. Influence of acute and chronic graft-versus-host disease on relapse and survival after bone marrow transplantation from HLA-identical siblings as treatment of acute and chronic leukemia. Blood. 1989;73: 1720-1728.

33. Truitt RL, Atasoylu AA. Impact of pretransplant conditioning and donor $\mathrm{T}$ cells on chimerism, graft-versus-host disease, graft-versus-leukemia reactivity, and tolerance after bone marrow transplantation. Blood. 1991;77:2515-2523.

34. OKunewick JP, Kociban DL, Machen LL, Buffo MJ. The role of CD4 and CD8 T cells in the graftversus-leukemia response in Rauscher murine leukemia. Bone Marrow Transplant. 1991;8:445452.

35. Faber LM, van der HJ, Goulmy E, et al. Recognition of clonogenic leukemic cells, remission bone marrow and HLA- identical donor bone marrow by $\mathrm{CD}^{+}$or $\mathrm{CD} 4^{+}$minor histocompatibility antigenspecific cytotoxic T lymphocytes. J Clin Invest. 1995;96:877-883.

36. Sosman JA, Oettel KR, Smith SD, Hank JA, Fisch $\mathrm{P}$, Sondel PM. Specific recognition of human leukemic cells by allogeneic T cells, II: evidence for HLA-D restricted determinants on leukemic cells that are crossreactive with determinants present on unrelated nonleukemic cells. Blood. 1990;75: 2005-2016.

37. van der HD, Goulmy E, Falkenburg JH, et al. Recognition of minor histocompatibility antigens on lymphocytic and myeloid leukemic cells by cytotoxic T-cell clones. Blood. 1994;83:10601066

38. Jiang YZ, Barrett AJ. Cellular and cytokine-mediated effects of CD4-positive lymphocyte lines generated in vitro against chronic myelogenous leukemia. Exp Hematol. 1995;23:1167-1172.

39. Jiang $Y Z$, Barrett J. The allogeneic CD4 ${ }^{+}$T-cellmediated graft-versus-leukemia effect. Leuk Lymphoma. 1997;28:33-42.

40. Ruggeri L, Capanni M, Casucci M, et al. Role of natural killer cell alloreactivity in HLA-mismatched hematopoietic stem cell transplantation. Blood. 1999;94:333-339.

41. Hauch M, Gazzola MV, Small T, et al. Anti-leukemia potential of interleukin-2 activated natural killer cells after bone marrow transplantation for chronic myelogenous leukemia. Blood. 1990;75: 2250-2262.

42. O'Kunewick JP, Kociban DL, Machen LL, Buffo MJ. Evidence for a possible role of asialo-GM1 positive cells in the graft-versus-leukemia repression of a murine type-C retroviral leukemia. Bone Marrow Transplant. 1995;16:451-456.

43. Zeis $M$, Uharek L, Glass B et al. Allogeneic NK cells as potent antileukemic effector cells after allogeneic bone marrow transplantation in mice. Transplantation. 1995;59:1734-1736.

44. Glass B, Uharek L, Zeis M, Loeffler H, MuellerRuchholtz W, Gassmann W. Graft-versus-leukaemia activity can be predicted by natural cytotoxicity against leukaemia cells. Br J Haematol. 1996; 93:412-420.

45. Jiang YZ, Barrett AJ, Goldman JM, Mavroudis DA. Association of natural killer cell immune recovery with a graft-versus-leukemia effect independent of graft-versus-host disease following allogeneic bone marrow transplantation. Ann $\mathrm{He}-$ matol. 1997;74:1-6.

46. Warren EH, Gavin M, Greenberg PD, Riddell SR Minor histocompatibility antigens as targets for T-cell therapy after bone marrow transplantation. Curr Opin Hematol. 1998:5:429-433.

47. Falkenburg JH, Goselink HM, van der HD, et al. Growth inhibition of clonogenic leukemic precursor cells by minor histocompatibility antigenspecific cytotoxic T lymphocytes. J Exp Med. 1991;174:27-33.

48. Mutis T, Verdijk R, Schrama E, Esendam B, Brand A, Goulmy E. Feasibility of immunotherapy 
From www.bloodjournal.org at SWETS SUBSCRIPTION SERVICES on November 26, 2007. For personal use only.

of relapsed leukemia with ex vivo-generated cytotoxic T lymphocytes specific for hematopoietic system-restricted minor histocompatibility antigens. Blood. 1999;93:2336-2341.

49. Bonnet D, Warren EH, Greenberg PD, Dick JE, Riddell SR. CD8(+) minor histocompatibility antigen-specific cytotoxic T lymphocyte clones eliminate human acute myeloid leukemia stem cells. Proc Natl Acad Sci U S A. 1999;96:8639-8644.

50. Orsini E, Alyea EP, Chillemi A, et al. Conversion to full donor chimerism following donor lymphocyte infusion is associated with disease response in patients with multiple myeloma. Biol Blood Marrow Transplant. 2000;6:375-386.

51. Lyons $A B$, Parish $C R$. Determination of lymphocyte division by flow cytometry. J Immunol Methods. 1994;171:131-137.

52. Acha-Orbea H, Held W, Waanders GA, et al. Exogenous and endogenous mouse mammary tumor virus superantigens. Immunol Rev. 1993; 131:5-25.

53. Williams MB, Butcher EC. Homing of naive and memory T lymphocyte subsets to Peyer's patches, lymph nodes, and spleen. J Immunol. 1997;159:1746-1752.
54. Johnson BD, McCabe C, Hanke CA, Truitt RL. Use of anti-CD3 epsilon $F\left(a b^{\prime}\right) 2$ fragments in vivo to modulate graft-versus-host disease without loss of graft-versus-leukemia reactivity after MHC-matched bone marrow transplantation. J Immunol. 1995;154:5542-5554.

55. Eto M, Mayumi H, Tomita $\mathrm{Y}$, Yoshikai $\mathrm{Y}$, Nomoto $\mathrm{K}$. Intrathymic clonal deletion of $\mathrm{V}$ beta $6^{+} \mathrm{T}$ cells in cyclophosphamide-induced tolerance to $\mathrm{H}$-2compatible, Mls-disparate antigens. J Exp Med. 1990;171:97-113.

56. Miconnet I, Roger T, Seman M, Bruley-Rosset M Critical role of endogenous Mtv in acute lethal graft-versus-host disease. Eur J Immunol. 1995; 25:364-368.

57. MacDonald HR, Lees RK, Chvatchko Y. CD $8^{+} \mathrm{T}$ cells respond clonally to Mls-1a-encoded determinants. J Exp Med. 1990;171:1381-1386.

58. Webb SR, Sprent J. Factors controlling the reactivity of immature and mature T cells to Mls antigens in vivo. Immunol Rev. 1993;131:169-188.

59. Agus DB, Surh CD, Sprent J. Reentry of T cells to the adult thymus is restricted to activated T cells. J Exp Med. 1991;173:1039-1046.

60. Fukushi N, Arase H, Wang B, et al. Thymus: a direct target tissue in graft-versus-host reaction after allogeneic bone marrow transplantation that results in abrogation of induction of self-tolerance. Proc Natl Acad Sci U S A. 1990;87:63016305.

61. Hollander GA, Widmer B, Burakoff SJ. Loss of normal thymic repertoire selection and persistence of autoreactive T cells in graft vs host disease. J Immunol. 1994;152:1609-1617.

62. Shlomchik WD, Couzens MS, Tang CB, et al Prevention of graft versus host disease by inactivation of host antigen-presenting cells. Science. 1999;285:412-415.

63. Antin JH, Childs R, Filipovich $\mathrm{AH}$, et al. Establishment of complete and mixed donor chimerism after allogeneic lymphohematopoietic transplantation: recommendations from a workshop at the 2001 tandem meetings. Biol Blood Marrow Transplant. 2001;7:473-485.

64. Bader P, Stoll K, Huber S, et al. Characterization of lineage-specific chimaerism in patients with acute leukaemia and myelodysplastic syndrome after allogeneic stem cell transplantation before and after relapse. Br J Haematol. 2000;108:761 768. 